$01.1 ; 07.2$

\title{
Численное моделирование вольт-амперной характеристики биполярного мемристора на основе оксида гафния
}

\author{
(C) А.Н. Алёшин, Н.В. Зенченко , О.А. Рубан \\ Институт сверхвысокочастотной полупроводниковой электроники им. В.Г. Мокерова РАН, \\ Москва, Россия \\ ฯ E-mail: Zenchenko.Nikolay@yandex.ru
}

Поступило в Редакцию 6 июня 2020г.

В окончательной редакции 22 марта 2021 г.

Принято к публикации 6 апреля 2021 г.

Разработана конечно-элементная модель, позволяющая рассчитывать вольт-амперную характеристику биполярного мемристора на основе оксида гафния $\mathrm{Pt} / \mathrm{HfO}_{2} / \mathrm{TiN}$, которая отражает как высокоомное, так и низкоомное состояние мемристора. Математическим базисом модели явились уравнения Максвелла для стационарного случая. Модель позволяет оценивать связь свойств материалов, входящих в конструкцию мемристора, с его рабочим током.

Ключевые слова: биполярный мемристор, оксид гафния, метод конечных элементов, моделирование.

DOI: 10.21883/PJTF.2021.13.51121.18415

В настоящее время активно ведутся разработки новых компьютерных технологий, таких как квантовые компьютеры и нейроморфные системы. Нейроморфная система представляет собой искусственный объект, который имитирует работу человеческого мозга. Принцип действия подобной системы заключается в „запоминании“ новой информации путем изменения проводимости контактов между искусственными нейронами (синапсами). Одним из вариантов создания подобной системы может явиться массив мемристоров. Мемристор представляет собой функциональное устройство с двумя электродами. В процессе его работы на верхний электрод мемристора подается постоянное напряжение различного знака, а нижний электрод заземляется. В большинстве случаев в качестве рабочего тела мемристора используют оксиды переходных металлов: $\mathrm{TiO}_{2}, \mathrm{HfO}_{2}, \mathrm{NiO}, \mathrm{Ta}_{2} \mathrm{O}_{5}$. В процессе работы мемристора происходит переключение режима его работы из высокоомного состояния HRS (HRS - high resistance state) в низкоомное состояние LRS (LRS - low resistance state) и обратно. После отключения напряжения мемристор не изменяет свое состояние и таким образом „запоминает“ последнее значение сопротивления. Принцип переключения режима работы мемристора реализуется за счет образования и разрушения в рабочем теле токопроводящих каналов (ТК), представляющих собой области повышенной проводимости с поперечным размером порядка $10 \mathrm{~nm}$ либо в виде кластеров положительно заряженных кислородных вакансий со специфическими механизмами переноса электрических зарядов [1], либо в виде отдельной фазы, обладающей электропроводностью [2]. Вольт-амперная характеристика (BAX) биполярного мемристора образует петлю гистерезиса, что лежит в основе использования данного электротехнического изделия в качестве ячейки с резистивной памятью. Разные ветви ВАХ соот- ветствуют двум разным режимам работы мемристора: LRS и HRS.

Целью исследования является симуляция работы мемристора на основе оксида гафния в биполярном режиме методом конечных элементов для расчета ВАХ при использовании в качестве математического базиса уравнений Максвелла в стационарном состоянии. В отличие от мемристоров на основе оксида титана, в которых основным металлом для электродов служит $\mathrm{Pt}$, в биполярных мемристорах на основе оксида гафния используются более разнообразные пары электродов, например такие пары, как $\mathrm{Pt}-\mathrm{TiN}[3,4]$, TiN-TiN [5], Hf-TiN [6,7], Ni-TaN [8], что при моделировании BAX облегчает подбор пары электродов исходя из специфических свойств каждого из них. При моделировании в качестве ТК выбиралась обладающая повышенной проводимостью фаза $\mathrm{HfO}_{x}(x-$ мольная доля кислорода, $x<2$ ) [9], образование которой при работе мемристора на основе оксида гафния было подтверждено прямыми структурными исследованиями [7].

Существует довольно много работ, посвященных описанию работы униполярных мемристоров (см., например, обзор [2]) с использованием тех или иных элементов моделирования ВАХ (в основном связанных с тепловыми эффектами, приводящими к разрушению ТК, что отражается на форме BAX). Однако для биполярных мемристоров число работ, посвященных моделированию BAX с привлечением представлений о ТК как об отдельной фазе, существенно меньше [10]. Отличительной особенностью настоящей работы является использование в ней уравнений Максвелла на основе применения метода конечных элементов [11], что можно классифицировать как моделирование ВАХ из „первых принципов“. Такой подход достаточно универсален и в принципе позволяет оценить возможность создания мемристора на 

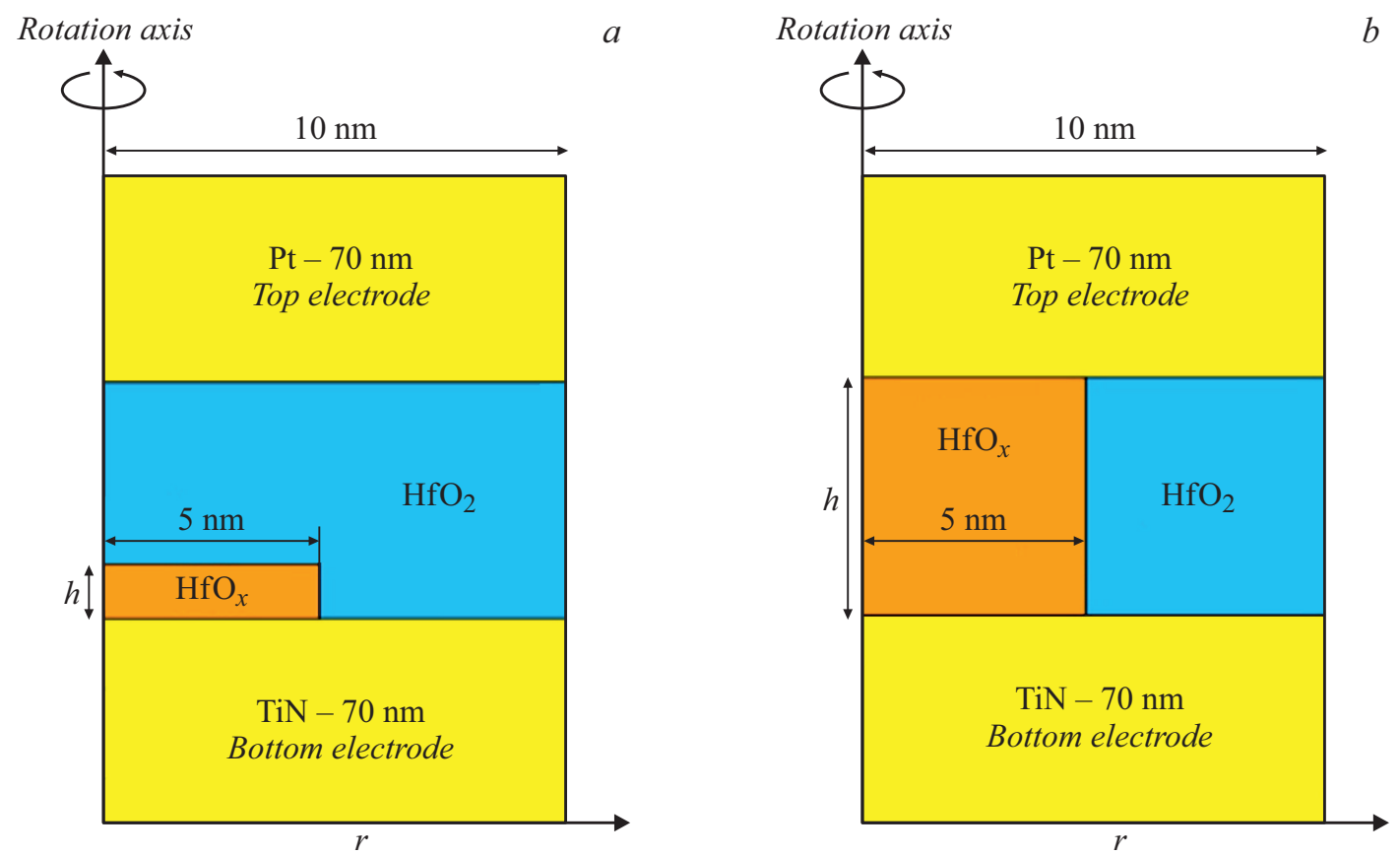

Рис. 1. Схематическое изображение конечно-элементной модели в цилиндрической системе координат, соответствующее различным стадиям формирования ТК. $a$ - начало формирования ТК, $b$ - полностью сформированный ТК.

основе широкого круга веществ. Ограничением в его использовании является недостаток сведений об электропроводности фаз, образующихся в процессе работы мемристора. Уравнения Максвелла для стационарного случая имеют вид

$$
\mathbf{i}=\sigma \mathbf{E}, \operatorname{div} \mathbf{i}=0, \quad \mathbf{E}=-\operatorname{grad} \varphi, \operatorname{div} \mathbf{E}=\rho / \varepsilon \varepsilon_{0},
$$

где $\mathbf{i}$ - плотность электрического тока, $\sigma$ - электропроводность, $\mathbf{E}$ - напряженность электрического поля, $\varphi$ - электрический потенциал, $\varepsilon_{0}$ - электрическая постоянная, $\varepsilon$ - относительная диэлектрическая постоянная, $\rho-$ плотность электрического заряда. Они позволяют рассчитать протекающий в мемристоре электрический ток $I$ в зависимости от подаваемого на верхний электрод мемристора напряжения $U$ при различной высоте ТК. При моделировании в качестве материала для верхнего электрода была выбрана $\mathrm{Pt}$, a для нижнего - TiN.

Выбор Pt в качестве верхнего электрода основывался на универсальных свойствах платины, которая по отношению к ионам кислорода в разных условиях может проявлять как блокирующие свойства, так и свойство прозрачности [2], что способствует протеканию окислительно-восстановительных реакций в области границы раздела $\mathrm{Pt}-$ оксид переходного металла. При подаче на верхний Pt-электрод положительного потенциала анионы кислорода решетки оксида переходного металла вступают с Pt в химическую реакцию, продуктами которой являются оксид платины и замещающие анионы кислорода положительно заряженные кислородные вакансии. Процесс генерации кислородных вакансий и их дрейф в электрическом поле лежат в основе механизма функционирования мемристора на основе оксидов переходных металлов.

Кроме способности к внутреннему окислению Pt обладает также способностью проявлять свойства катализатора, разлагая в силу хемосорбции молекулы адсорбированного на ее поверхности атмосферного кислорода (двухатомного нейтрального газа) на отрицательно заряженные ионы кислорода, что, согласно [12], приводит к вторичному окислению рабочего тела мемристора, т.е. к процессу замещения кислородных вакансий ионами кислорода. Процесс вторичного окисления происходит более интенсивно при подаче на Pt-электрод отрицательного напряжения. Используемый в качестве нижнего электрода нитрид титана $\mathrm{TiN}$ в рамках данной модели обладал инертными свойствами.

Модель мемристора была построена в цилиндрической системе координат (рис. 1). Радиус $r_{f}$ растущего в виде цилиндра слоя фазы $\mathrm{HfO}_{x}$ принимался равным $5 \mathrm{~nm}$, а радиус всей цилиндрической конструкции $r_{m}$ был равен $10 \mathrm{~nm}$. Высота слоя оксида гафния $\left(\mathrm{HfO}_{2}\right)$ принималась равной $5 \mathrm{~nm}$, при этом высоту ТК $h$, имитируя рост фазы $\mathrm{HfO}_{x}$, варьировали в пределах $0-5 \mathrm{~nm}$. Высота верхнего и нижнего электродов мемристора равнялась $70 \mathrm{~nm}$. При достижении $h=5 \mathrm{~nm}$ электрическая цепь замыкалась, мемристор переходил в состояние LRS, а протекающий в цепи ток подчинялся закону Ома. Принятые в модели размеры элементов конструкции мемристора соответствуют реально создаваемым объектам [3-5].

Работа мемристора определялась двухполярным сигналом треугольного профиля, который показан на рис. 2. 


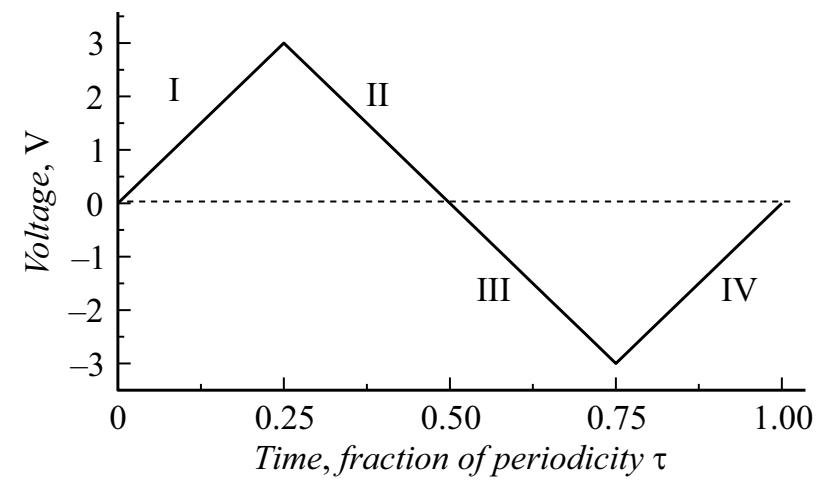

Рис. 2. Двухполярный сигнал треугольного профиля, развернутый во времени с периодом $\tau$, подаваемый на верхний электрод мемристора при моделировании ВАХ. Римскими цифрами обозначены различные участки сигнала, соответствующие положительному (участки I и IV) и отрицательному (участки II и III) склонам профиля.

На участке I двухполярного сигнала непрерывно генерируемые в области Pt-электрода кислородные вакансии в результате дрейфа собираются в области инертного TiN-электрода (в данном случае являющегося катодом) и тем самым создают предпосылки для образования и роста обедненной в отношении кислорода фазы $\mathrm{HfO}_{x}$. На участках II и III сигнала вплоть до подачи на верхний Pt-электрод мемристора максимального (по абсолютной величине) отрицательного напряжения сформированный на участке I электрического сигнала ТК (фаза $\mathrm{HfO}_{x}$ ) в силу инерционности процессов фазообразования оставался стабильным. При этом избыточные кислородные вакансии, образующиеся на участке II сигнала, нивелируются на участке III сигнала. При подаче на верхний Pt-электрод отрицательного напряжения (участок IV двухполярного сигнала) в рабочем теле мемристора возможны отрицательные отклонения концентрации вакансий от равновесной (в силу процесса вторичного окисления в области Рt-электрода), и, следовательно, в этом случае будет происходить растворение фазы $\mathrm{HfO}_{x}$.

Предложенный механизм перехода мемристора в состояние LRS является гетерогенным процессом, который характеризуется двумя различными стадиями: 1) стадией подвода (дрейфа) кислородных вакансий к катоду; 2) стадией образования фазы $\mathrm{HfO}_{x}$, которую можно представить как химическую реакцию первого порядка $\mathrm{HfO}_{2} \rightarrow \mathrm{HfO}_{x}$. Скорость такой реакции $\omega_{2}=k c_{x}$, где $k-$ постоянная скорости реакции, $c_{x}-$ концентрация кислородных вакансий в фазе $\mathrm{HfO}_{x}$. Поскольку в процессе реакции кислородные вакансии расходуются, необходимым условием для ее протекания будет неравенство $c_{x}<c_{0}$, где $c_{0}-$ концентрация кислородных вакансий вдали от границы раздела фаз. Условие $c_{x}<c_{0}$ соответствует концепции пограничного слоя, примыкающего к границе раздела фаз и характеризующегося коэффициентом массопереноса $\beta$. Скорость подвода вакансий к границе раздела фаз $\omega_{1}$ в этом случае будет определять- ся выражением $\omega_{1}=\beta\left(c_{0}-c_{x}\right)$. Если стадия подвода кислородных вакансий к границе раздела фаз является лимитирующей $(\beta \ll k)$, что типично для двухстадийных процессов, то в стационарном случае $\left(\omega_{1}=\omega_{2}\right)$ скорость образования фазы $\mathrm{HfO}_{x} \omega_{2}=\beta c_{0}[13]$, т. е. определяется исключительно параметрами внешнего массопереноса. Таким образом, в стационарном случае скорость реакции $\mathrm{HfO}_{2} \rightarrow \mathrm{HfO}_{x}$ можно исключить из анализа процесса, и базовым выражением для моделирования ВАХ будет выражение для скорости дрейфа кислородных вакансий в электрическом поле.

Общее выражение для скорости дрейфа заряженных вакансий $v$ под действием электрического поля $E$ имеет вид [14]:

$$
v=\frac{2 D_{v}}{a} \sinh \left(\frac{q a E}{2 k_{\mathrm{B}} T}\right),
$$

где $a$ - период кристаллической решетки, $D_{v}-$ коэффициент диффузии вакансий, $q-$ заряд вакансии, $k_{\mathrm{B}}-$ постоянная Больцмана, $T-$ абсолютная температура. Вводя характерную величину электрического поля $E_{0}=2 k_{\mathrm{B}} T / q a$, а также используя такую кинетическую константу дрейфующей в электрическом поле вакансии, как подвижность $m_{v}\left(m_{v}=q D_{v} / k_{\mathrm{B}} T\right)$, выражение (2) можно представить в виде

$$
v=m E_{0} \sinh \left(\frac{E}{E_{0}}\right),
$$

удобном для моделирования. В случае миграции кислородных вакансий в оксиде гафния при комнатной температуре $(T=300 \mathrm{~K})$ величина $E_{0}$ равна $5 \cdot 10^{7} \mathrm{~V} / \mathrm{m}$, что для нашей модели мемристора соответствует напряжению $U_{0}=0.25 \mathrm{~V}$. Выражение (3) легко переформатировать, связав $v$ с переменной $U$, что необходимо сделать для расчета зависимости $I(U)$.

Высота слоя растущей фазы $\mathrm{HfO}_{x}$ в каждый момент времени при постоянном значении $U$ определяется выражением $h=v t$, где $t-$ время. В общем случае $h$ является двухпараметрической функцией $h=h(U, t)$, однако учитывая, что функция $y=\sinh \left(U / U_{0}\right)$ имеет экспоненциальный характер, $h$ можно представить в виде

$$
h=K_{0} \sinh \left(\frac{U}{U_{0}}\right),
$$

где $K_{0}$ является полуэмпирической константой, включающей в себя характерное время рабочего цикла мемристора, которое было использовано нами для моделирования ВАХ. Использование выражения (4) при расчете ВАХ позволяет исключить фактор времени из задачи.

В [4] было показано, что переход биполярного мемристора Pt/ $/ \mathrm{HfO}_{2} / \mathrm{TiN}$ в состояние LRS происходит в районе $U=2.2 \mathrm{~V}$. Подставляя в (4) $h=5 \mathrm{~nm}$ и $U=2.2 \mathrm{~V}$, получаем $K_{0}=1.51 \cdot 10^{-3} \mathrm{~nm}$. Это значение $K_{0}$ мы использовали при расчете тока $I$ при всех значениях $U$. Электрические и диэлектрические свойства веществ $\mathrm{TiN}, \mathrm{Pt}$, $\mathrm{HfO}_{2}$ и $\mathrm{HfO}_{x}$, определяющих архитектонику мемристора, 
Свойства веществ, используемых в модели $[15,16]$

\begin{tabular}{c|c|c}
\hline Вещество & $\sigma, \mathrm{S} / \mathrm{m}$ & $\varepsilon$ \\
\hline $\mathrm{TiN}$ & $10^{6}$ & $-10^{6}$ \\
$\mathrm{HfO}_{2}$ & 9 & 25 \\
$\mathrm{HfO}_{x}$ & $2 \cdot 10^{4^{*}}$ & $-10^{6}$ \\
$\mathrm{Pt}$ & $5 \cdot 10^{6}$ & $-10^{6}$
\end{tabular}

${ }^{*}$ Величина $\sigma$ фазы $\mathrm{HfO}_{x}$ рассчитана на основании ВАХ, приведенной в [6], и в соответствии с размерами ТК, указанными в [7].

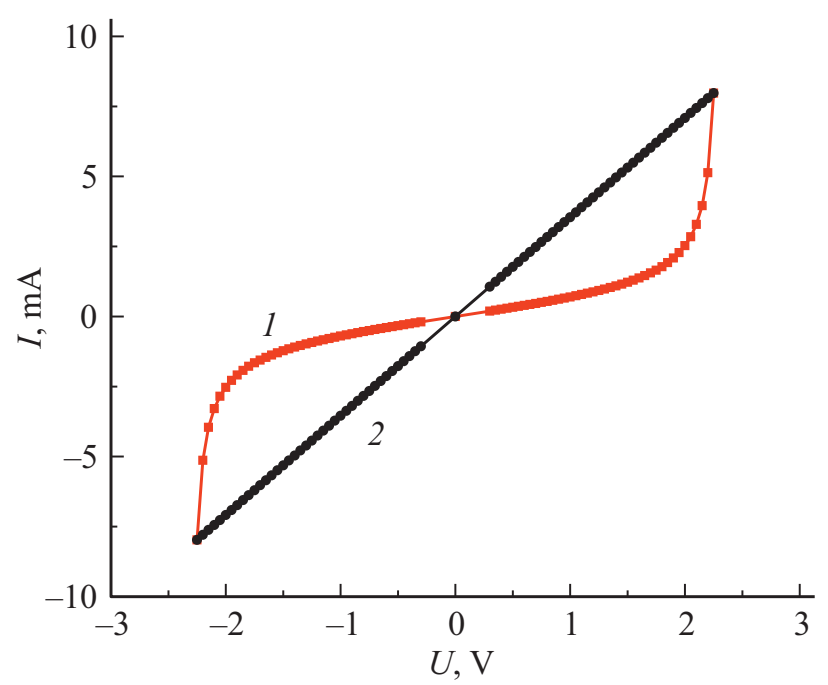

Рис. 3. Модельная ВАХ мемристора на основе $\mathrm{HfO}_{2}$ для ТК, имеющего форму цилиндра с радиусом $r_{f}=5 \mathrm{~nm}$. $1-$ ветви BAX, соответствующие режиму HRS, 2 - режиму LRS.

были взяты из работ $[15,16]$ (см. таблицу). Рассчитанная BAX показана на рис. 3. Видно, что ВАХ имеет вид петли гистерезиса. Во втором и третьем циклах наличие в структуре мемристора ТК с металлическим типом проводимости обеспечивало выполнение закона Ома. Характер изменения ВАХ в первом и четвертом циклах работы мемристора близок к экспоненциальному. Такой вид ветвей $\mathrm{BAX}$ соответствует известному положению термодинамики необратимых процессов, согласно которому максимальная скорость того или иного фазового превращения достигается в условиях максимального отклонения от равновесия.

Таким образом, выполнено моделирование работы биполярного мемристора на основе оксида гафния методом конечных элементов при использовании в качестве математического базиса уравнений Максвелла для стационарного случая. Режим работы мемристора состоял из четырех последовательных временны́х интервалов, соответствующих различным участкам двухполярного сигнала треугольного профиля. ВАХ мемристора имела вид петли гистерезиса, что соответствует известным экспериментальным данным. На положительных склонах двухполярного сигнала зависимость тока $I(U)$ имела экспоненциальный характер, а на отрицательных склонах выполнялся закон Ома. Описанная процедура расчета BAX будет использована в дальнейшем для моделирования работы мемристора при температурных воздействиях.

\section{Финансирование работы}

Работа выполнена при финансовой поддержке Российского фонда фундаментальных исследований (грант № 19-29-03003 MK).

\section{Конфликт интересов}

Авторы заявляют, что у них нет конфликта интересов.

\section{Список литературы}

[1] G. Bersuker, D.C. Gilmer, D. Veksler, P. Kirsch, L. Vandelli, A. Padovani, L. Larcher, K. McKenna, A. Shluger, V. Iglesias, M. Porti, M. Nafria, J. Appl. Phys., 110, 124518 (2011). DOI: $10.1063 / 1.3671565$

[2] K.M. Kim, D.S. Jeong, C.S Hwang, Nanotechnology, 22, 254002 (2011). DOI: 10.1088/0957-4484/22/25/254002

[3] L. Goux, Y.-Y. Chen, L. Pantisano, X.-P. Wang, G. Groeseneken, M. Jurczak, D.I. Wouters, Electrochem. Solid-State Lett., 13, G54 (2010). DOI: 10.1149/1.3373529

[4] L. Goux, P. Czarnecki, Y.-Y. Chen, L. Pantisano, X.-P. Wang, R. Degraeve, B. Govorenau, M. Jurczak, D.J. Wouters, L. Altimime, Appl. Phys. Lett., 97, 243509 (2010). DOI: $10.1063 / 1.3527086$

[5] F. Nardi, S. Larentis, S. Balatti, D.C. Gilmer, D. Ielmini, IEEE Trans. Electron Dev., 59, 2461 (2012). DOI: 10.1109/TED.2012.2202319

[6] D.J. Wouters, L. Zhang, A. Fantini, R. Degraeve, L. Goux, Y.-Y. Chen, B. Govorenau, G.S. Kar, IEEE Electron Dev. Lett., 33, 1186 (2012). DOI: 10.1109/LED.2012.2198789

[7] S. Privetera, G. Bersuker, B. Butcher, A. Kalantarian, S. Lombardo, C. Bongiorno, R. Geer, D.C. Gilmer, P.D. Kirsch, Microelectron. Eng., 109, 75 (2013). DOI: 10.1016/j.mee.2013.03.145

[8] V.A. Voronovskii, V.S. Aliev, A.K. Gerasimova, D.R. Islamov, Mater. Res. Express, 6, 076411 (2019). https://doi.org/10.1088/2053-1591/ab11aa

[9] E. Hildebrandt, J. Kurian, M.M. Muller, T. Schroeder, H.J. Kleebe, A. Lambert, Appl. Phys. Lett., 99, 112902 (2011). DOI: $10.1063 / 1.3637603$

[10] S. Larentis, F. Nardi, S. Balatti, D.C. Gilmer, D. Ielmini, IEEE Trans. Electron Dev., 59, 2468 (2012). DOI: 10.1109/TED.2012.2202320

[11] Э.П. Шурина, М.Ю. Великая, М.П. Федорук, Вычислительные технологии, 5 (6), 99 (2000).

[12] D.S. Jeong, H. Schroeder, U. Breuer, R. Waser, J. Appl. Phys., 104, 123716 (2008). DOI: 10.1063/1.3043879

[13] Б.С. Бокштейн, М.И. Менделев, Краткий курс физической химии (ЧеРо, М., 1999).

[14] M. Noman, W. Jiang, P.A. Salvador, M. Skowronski, J.A. Bain, Appl. Phys. A., 102, 877 (2011). DOI: $10.1007 / \mathrm{s} 00339-011-6270-\mathrm{y}$

[15] CRC handbook of chemistry and physics, 88th ed, ed. by D.R. Lide (Taylor and Francis Group, Boca Raton, 2008).

[16] C.L. Yaws, The Yaws handbook of physical properties for hydrocarbons and chemicals, 2nd ed. (Gulf Professional Publ., Houston, 2015). 